\title{
Quantitative determination of Levomepromazine in pharmaceuticals by spectrophotometric method as its sulfoxide
}

\author{
Mykola Ye. Blazheyevskiy, Olena O. Mozgova* \\ National University of Pharmacy, 53 Pushkinska str., Kharkiv, 61002, Ukraine \\ elena.mozgovaya25@gmail.com
}

Keywords: Levomepromazine hydrochloride, Levomepromazine sulfoxide, Diperoxyazelaic acid, indirect spectrophotometry.

The oxidative derivatization method using Diperoxyazelaic acid for the indirect spectrophotometric determination of Levomepromazine hydrochloride is presented. Diperoxyazelaic acid is introduced as a derivatizing agent for Levomepromazine, yielding the sulfoxides. This reaction product was successfully used for the spectrophotometric determination of the Levomepromazine hydrochloride. The UV spectroscopic detection of the sulfoxide proved to be a more robust and sensitive method. The elaborated method allowed the determination of Levomepromazine hydrochloride in the concentration range of $3-150 \mu \mathrm{g} / \mathrm{mL}$. The limit of quantification, LOQ (10S) is $2.85 \mu \mathrm{g} / \mathrm{mL}$. A new spectrophotometric technique was developed and the possibility of quantitative determination of Levomepromazine in Tisercin Solution for Injection $25 \mathrm{mg} / \mathrm{mL}$ was demonstrated. The present method is precise, accurate and other excipients: anhydrous citric acid, monothioglycerol, sodium chloride did not interfere. $\operatorname{RSD}=1.24 \%(\delta=-0.02 \%)$.

\section{Introduction}

Chemically, Levomepromazine hydrochloride (Tisercin $\AA$ ) is a derivative of phenothiazine with dialkylaminoalkyl substituents in side chains of molecules in position 10 (Fig. 1), with antipsychotic activity. Levomepromazine with methoxy group in position 2 has high activity and rapid sedative effect and is used for acute psychosis treatment (depressive-paranoid schizophrenia, psychomotor agitation, alcoholic psychosis, etc.) [1]. In particular, it is produced in the form of a powder of Levomepromazine hydrochloride and maleate tablets, $0.025 \mathrm{~g}$ of tablets under the trade name of Tisercin $\AA$, a solution for injections of $25 \mathrm{mg} / \mathrm{mL}$ (as Levomepromazine base); as auxiliary substances: sodium chloride, citrate acid, monothioglycerol and water for injection.

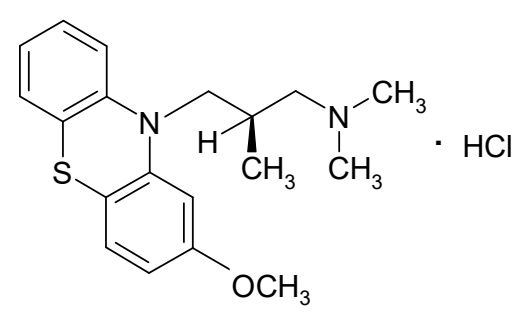

Figure 1. The structural formula for Levomepromazine Hydrochloride (Syn. Methotremprozine Hydrochloride)

The literature shows a wide variety of analytical techniques used for its determination, 
such as liquid chromatographic methods with different detectors [2-5], gas chromatographymass spectrometry [6] fluorimetric [7], voltammetric [8-10] and other methods [11,12]. A lot of them employed HPLC technique which allows simultaneous determination of Levomepromazine and its metabolites in miscellaneous samples: brain tissues, human plasma or serum. In addition to these electromigration techniques like capillary zone electrophoresis [11], solid-phase extraction [12] was used for the separation and the determination of Levomepromazine and its metabolites too.

The quality control of Levomepromazine pharmaceuticals requires, due to its relatively high content in preparations, less selective and less sophisticated methods like titrimetry or/and spectrophotometry. The European Pharmacopoeia recommends to determinate the content of the main substance of Levomepromazine maleate by the method of acidimetry in acetic anhydride medium, potentiometrically; Levomepromazine hydrochloride by alkalimetry in a waterisopropanol medium, potentiometric recording of the endpoint of titration; Levomepromazine maleate tablets and injection solutions - by direct spectrophotometry using its light absorption (characterized by K-band of the conjugate system of the phenothiazine ring in the UV spectrum) at $254 \mathrm{~nm}$ in methanol or water (Levomepromazine hydrochloride) at $302 \mathrm{~nm}$ [13] and in injection solution of Levomepromazine maleate with ascorbic acid and metabisulfite or monothioglycerol by HPLC method [14].

With the development of modern pharmaceutical chemistry, the need arises to develop new methods of determination using contemporary analytical techniques. Recently, was proposed reliable and accurate UVspectrophotometric methods for the simultaneous assay of Levomepromazine hydrochloride and its sulphoxide [15,16]. One of them has applied derivatization of spectra for the separation of overlapped signals. The second one has utilized a bivariate calibration algorithm. The elaborated methods have been applied for the determination of studied compounds in synthetic mixtures without initial separation. Additionally, the proposed procedures have been used for assaying the Levomepromazine content in coated tablets "Tisercin". The obtained results have been compared with a declared value. The value of relative error less then $\pm 1 \%$ has shown an excellent accuracy of both spectrophotometric methods [15].

The scientific literature describes methods for the quantitative determination of Levomepromazine as an intermediate product of oxidation of the cation-radical Phenthiazonium Levomepromazine. However, most of them require long-term heating and/or containment for the development of color. Almost all spectrophotometric methods based on the formation of colored cation-radicals strongly depend on the concentration of acid or oxidizer, 
and their colored forms are unstable, the color is retained for 20-30 minutes [17].

Increasing selectivity and sensitivity of a determination is a promising approach based on the detection of API in the form of a derivative obtained with the help of a certain analytical reagent. The chemical transformation is subjected to a functional group that is part of the molecule of the active substance and is not part of the molecules of auxiliary substances (filler), and thus the selectivity of the determination of the API itself is achieved [18].

Chemical derivatization fall under the category of indirect spectrophotometric analysis and the compounds of interest are often converted to those with different spectral properties. One peculiar procedural step is the utilization of excess reagent in order to ensure complete conversion of the analyte and thereby increasing the dynamic working range possible. Majority of chemical derivatization reactions involve conversion of the analytes to molecules with longer chromophores hence absorption in the visible region and or conversion to species with hyperchromic absorption. Chemical derivatization may be adopted in instances where the analyte absorbs weakly in the UV region as is common with most drugs, where interference by irrelevant absorption is present, where there is a need to improve selectivity of the procedure or when cost implications will favour adoption of a colorimetric method to that of a UV-VIS spectrophotometer [19].
The accuracy of this determination is higher than other common methods, because there is no need for chromatographic separation or extraction of the active component and calibration according to the relevant standard. Only under certain optimal conditions, it is necessary to process the solution of the preparation with the reagent, converting its active substance into the corresponding compound, which will have the best spectral characteristics - more favorable for determination by spectrophotometry method [20]. So, is possible to carry out the quantitative determination of derivatives of phenothiazine using their oxidation products, the corresponding sulfoxides. The molar absorption coefficient of the band of the newly formed product in a wavelength range of $300-360 \mathrm{~nm}$ is higher than that of the salt form of the unoxidized derivative of phenothiazine. Besides, as a result of oxidation, there is a bathochromic shift in the absorption band of the analyzed product, which further increases the selectivity of the analysis.

We have proposed a quantitative determination of Levomepromazine hydrochloride by indirect spectrophotometry in the form of a corresponding sulfoxide, which was obtained with the help of diperoxyazelaic acid as a new analytical reagent. The scheme of Soxidation of Levomepromazine via diperoxyazelaic acid in an acidic medium is shown in Fig. 2. 


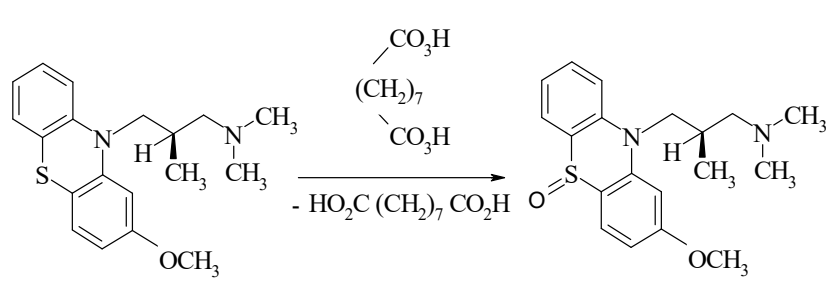

Figure 2. Scheme of S-oxidation of Levomepromazine by diperoxyazelaic acid in an acid medium

\section{Experimental part}

\section{Materials and methods}

Diperoxyazelaic acid (Nonanebis (peroxoic acid)). It was synthesized by acylation of hydrogen peroxide with azelaic acid in concentrated sulfuric acid according to a wellknown Swern method [21].

Levomepromazine hydrochloride (LV), (2)-(2-methoxyphenothiazin10-yl)-2-methyl$\mathrm{N}, \mathrm{N}$-dimethylpropylamine $\cdot \mathrm{HCl} \quad\left(\mathrm{C}_{19} \mathrm{H}_{25} \mathrm{ClN}_{2} \mathrm{OS}\right)$ was purchased from EGTO, Budapest, Hungary; MW : $364.932 \mathrm{~g} / \mathrm{mol}$.

Sample preparation is Tisercin $\AA$, Levomepromazine hydrochloride $25 \mathrm{mg} / \mathrm{mL}$, solution for Injection of $1 \mathrm{~mL}$. Tisercin ${ }^{\circledR}$ solution for injection, 1 vial contains $25 \mathrm{mg}$ of Levomepromazine hydrochloride calculated on Levomepromazine base; excipients: citric acid anhydrous $(9 \mathrm{mg})$, monothioglycerol $(7.5 \mathrm{mg})$, sodium chloride (6 mg), water for injections (up to $1 \mathrm{~mL})$. Manufactured by EGIS Pharmaceuticals PLC, Hungary; Lot: 23F0317.

Preparation of a solution of diperoxyazelaic acid with a concentration of $0.0085 \mathrm{M}$. A solution of about $0.2 \mathrm{~g}$ of diperoxyazelaic acid powder is dissolved in 100 $\mathrm{mL}$ of $50 \%$ ethanol. The exact content is determined by the method of iodometric titration [20].

Stock standard solution of potassium iodide (KI), $10 \% .10 \mathrm{~g}$ of potassium iodide dissolved in freshly boiled and cooled water and bring the volume of the solution up to $100 \mathrm{~mL}$.

Stock standard solution of sodium thiosulfate $\left(\mathrm{Na}_{2} \mathrm{~S}_{2} \mathrm{O}_{3} \times 5 \mathrm{H}_{2} \mathrm{O}\right), 0.1 \mathrm{~mol} / \mathrm{L}$. It was prepared from a fixed standard titer. More dilute solutions were obtained by appropriate dilution of the initial solution twice with distilled water.

Stock standard solution of hydrochloric acid $(\mathrm{HCl}), 0.2 \mathrm{~mol} / \mathrm{L}$. It was prepared from a fixed standard titre.

Stock standard solution of sulfuric acid $\left(\mathrm{H}_{2} \mathrm{SO}_{4}\right), 0.1 \mathrm{~mol} / \mathrm{L}$. It was prepared from a fixed standard titre. $0.02 \mathrm{~mol} / \mathrm{L}$ solution of sulfuric acid was prepared by appropriate double dilution with distilled water.

Stock standard solution of Levomepromazine hydrochloride $(0.25 \mathrm{mg} / \mathrm{mL}$, calculated on the Levomepromazine base $\left(\mathrm{C}_{19} \mathrm{H}_{24} \mathrm{~N}_{2} \mathrm{OS}\right)$ was prepared from the pure product Levomepromazine hydrochloride by dissolving an appropriate weight in $100 \mathrm{ml}$ of $0.02 \mathrm{M}$ solution of sulfuric acid at $+20^{\circ} \mathrm{C}$.

Registration of Levomepromazine hydrochloride solutions and products of its oxidation spectra, as well as the measurement of absorbance of solutions, was performed in a $1 \mathrm{~cm}$ quartz cuvette on an Evolution 60S UV-Visible Thermo-Scientific Spectrophotometer (USA) against a solution without the analyzed 
Phenothiazine derivative or double distilled water (compensation solution).

Measurement of the $\mathrm{pH}$ of the solution was carried out by electrometric method using the glass electrode ESL-43-07 and the "Ionomer I-130".

The procedure of obtaining results for the calibration graph.

Using a pipette sample $1.00 ; 2.00 ; 6.00$; 10.00; 20.00 and $30.00 \mathrm{~mL}$ of Levomepromazine standard solution and transferred to $50 \mathrm{~mL}$ volumetric flasks, then add $10 \mathrm{~mL}$ of $0.1 \mathrm{M}$ sulfuric acid solution and $2.0 \mathrm{~mL}$ of $0.0085 \mathrm{M}$ of diperoxyazelaic acid solution to each flask, and dilute to the volume with double distilled water, plug and mix thoroughly by turning the flask 7 to 10 times. The solution was photometrised at an analytical wavelength of $333 \mathrm{~nm}$ in a quartz cuvette with a thickness of $1 \mathrm{~cm}$. Double distilled water was used as a compensating solution.

The graph was positioned in the following coordinates: the light absorption on the ordinate axis and the corresponding content of Levomepromazine in the form of sulfoxide on the abscissa axis (Fig.4). The graph equation coefficients have been calculated by the least square method.

Method of determining the content of Levomepromazine in a solution for injection of $25 \mathrm{mg} / \mathrm{mL}$. The precisely measured volume of $1.00 \mathrm{~mL}$ of a solution of Tisercin for injection is transferred to a $100 \mathrm{~mL}$ volumetric flask and diluted with a solution of $0.02 \mathrm{M}$ sulfuric acid solution to $100 \mathrm{~mL}$. Pour the flask and mix it thoroughly. $10 \mathrm{~mL}$ of solution obtained was taken with a pipette and transferred to a $50 \mathrm{~mL}$ volumetric flask, $10 \mathrm{~mL}$ of a $0.1 \mathrm{M}$ solution of sulfuric acid and $2.0 \mathrm{~mL}$ of a $0.0085 \mathrm{M}$ solution of diperoxyazelaic acid were added successively, bring the volume of the solution to the mark by double distilled water, plug and mix thoroughly. The solution was photometrised at an analytical wavelength of $333 \mathrm{~nm}$ in a quartz cuvette with a thickness of $1 \mathrm{~cm}$ against double distilled water as a compensating solution.

Similar procedures were carried out for a standard solution of Levomepromazine hydrochloride: $10 \mathrm{~mL}$ of Levomepromazine hydrochloride solution was taken with a pipette and transferred to a $50 \mathrm{~mL}$ volumetric flask, $10 \mathrm{~mL}$ of a $0.1 \mathrm{M}$ solution of sulfuric acid and $2.0 \mathrm{~mL}$ of a $0.0085 \mathrm{M}$ solution of diperoxyazelaic acid were added successively, bring the volume of the solution to the mark by double distilled water, plug and mix thoroughly. The solution was photometrised at an analytical wavelength of $333 \mathrm{~nm}$ in a quartz cuvette with a thickness of $1 \mathrm{~cm}$ against double the distilled water as a compensating solution.

The content of Levomepromazine hydrochloride (as Levomepromazine base $\left(\mathrm{C}_{19} \mathrm{H}_{24} \mathrm{~N}_{2} \mathrm{OS}\right)(X)$ in $\mathrm{mg}$ to $1 \mathrm{~mL}$ of solution for injection) was calculated by the formula:

$$
X=\left(c_{\mathrm{st}} \times A_{\mathrm{x}} \times 100 \times 5\right) /(A \times 5)
$$

where $A_{\mathrm{x}}$ is the optical density in the experiment with Tisercin solution; $A$ is the optical density in 
the experiment with Levomepromazine reference standard solution;

$C_{\text {st }}$ is the content of the drug in reference standard solution, $\mathrm{mg} / \mathrm{mL}$; 5 is dilution; 100 is the flask volume for pharmaceutical or standard solution preparation.

\section{Results and discussion}

The linear dependence of the absorbance is observed in the Levomepromazine concentration range $3-150 \mu \mathrm{g} / \mathrm{mL}$, the calibration curve equation was $A=0.0076 \times C$ $(r=0.999)($ Fig. 3 and 4$)$.

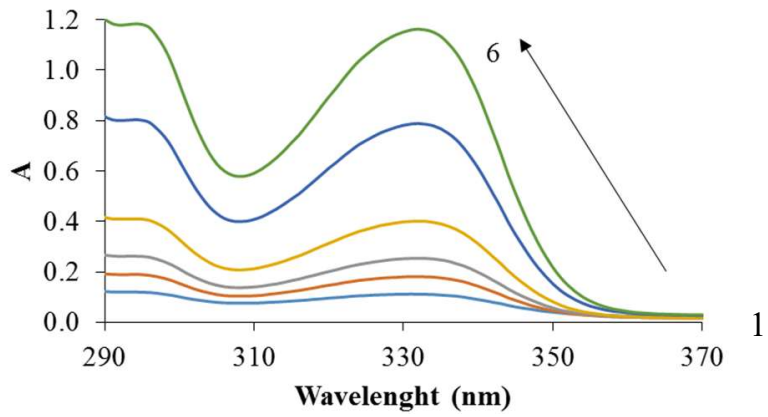

Figure 3. UV spectra of light absorption of Levomepromazine sulfoxide solutions: $C, \mathrm{~mol} / \mathrm{L}$, $1-1.5 \times 10^{-5} ; 2-3.0 \times 10^{-5} ; 3-4.5 \times 10^{-5} ; 4-7.0 \times 10^{-5}$; $5-1.5 \times 10^{-4} ; 6-2.2 \times 10^{-4}$

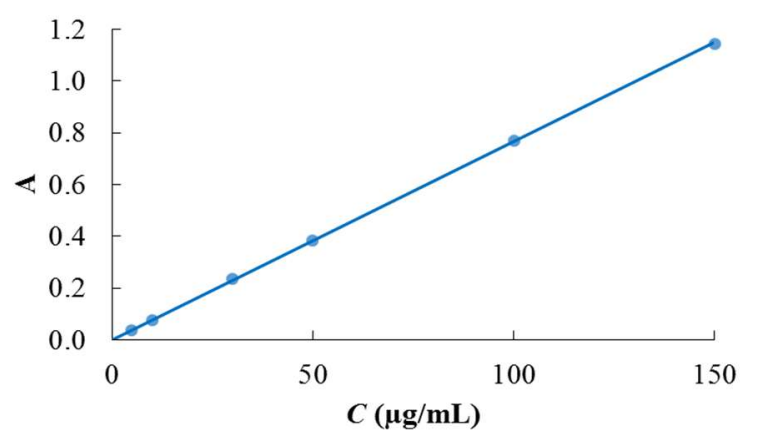

Figure 4. The calibration graph of the Levomepromazine quantitative determination in the form of a corresponding sulfoxide. $0.02 \mathrm{~mol} / \mathrm{L} \mathrm{H}_{2} \mathrm{SO}_{4}$

Analytical characteristics of the calibration graph of the Levomepromazine indirect spectrophotometric determination procedure are given in Table 1.

Table 1. Optical characteristics and statistical data for the regression equation the proposed method

\begin{tabular}{|l|l|}
\hline Optical characteristics & Parameters \\
\hline$\lambda_{\max }(\mathrm{nm})$ & 333 \\
\hline Beer's law limit $(\mu \mathrm{g} / \mathrm{mL})$ & $3-150$ \\
\hline $\begin{array}{l}\text { Molar absorptivity } \\
(\mathrm{L} / \text { mol } \times \mathrm{cm})\end{array}$ & $(5.75 \pm 0.4) \times 10^{3}$ \\
\hline Correlation coefficient $(\mathrm{r})$ & 0.999 \\
\hline $\begin{array}{l}\text { Linear regression } \\
\text { equation }\end{array}$ & $A=0.0076 \times C$ \\
\hline Sy/x & 0.00357 \\
\hline Slope $(b \pm \Delta b)$ & $0.00763 \pm 0.00008$ \\
\hline Intercept $(a \pm \Delta a)$ & $0.0025 \pm 0.0060$ \\
\hline S.D. of slope $\left(S_{b}\right)$ & 0.000028 \\
\hline S.D. of intercept $\left(S_{a}\right)$ & 0.0022 \\
\hline LOD $(3 S)(\mu \mathrm{g} / \mathrm{mL})$ & 0.94 \\
\hline LOQ $(10 S)(\mu \mathrm{g} / \mathrm{mL})$ & 2.85 \\
\hline
\end{tabular}
concentration of Levomepromazine in $\mu \mathrm{g} / \mathrm{mL}$.

Table 2 shows the results of the determination of Levomepromazine hydrochloride in a solution for injections of $25 \mathrm{mg}$ (up to $1.00 \mathrm{~mL}$ ) received by the newly developed method. It shows that the proposed method of performing the analysis allows us to determine the substituted derivative of phenothiazine (Levomepromazine hydrochloride) in the dosage forms with reliable accuracy. The relative standard deviation does not exceed $\pm 1.24 \%$. The obtained results are in good correlation with the data of the determination of phenothiazine derivative by the recommended Pharmacopoeial method of liquid chromatography (Ph Eur). Limit of detection (LOD) is $0.94 \mu \mathrm{g} / \mathrm{mL}$ and limit of quantification (LOQ) is $2.85 \mu \mathrm{g} / \mathrm{mL}$. 
Table 2. The results of the quantitative determination of Levomepromazine of $25 \mathrm{mg}$ in the Tisercin ${ }^{\circledR}$ solution for injection

\begin{tabular}{|c|c|c|}
\hline Taken & $\begin{array}{c}\text { Found, } \\
\mathrm{mg} / \mathrm{mL}\end{array}$ & $\begin{array}{c}\text { Metrological } \\
\text { characteristics } \\
\mathrm{P}=0.95\end{array}$ \\
\hline $1.00 \mathrm{~mL}$ & 25.45 & $\bar{x}=25.20$ \\
$(25.25 \mathrm{M \Gamma} \pm 5 \%)$ & 25.08 & $\mathrm{~S}=0.3124$ \\
Tisercin $\AA$ solution & 25.78 & $\mathrm{~S} \bar{x}=0.1181$ \\
for injections, & 24.90 & $\bar{x}=0.2893$ \\
Egis (Budapest, & 24.98 & $\Delta{ }^{-}$ \\
Hungary); Lot: & 25.02 & $R S D=1.24 \%$ \\
23F0317 & 25.16 & $\delta^{*}=-0.02 \%$ \\
\hline
\end{tabular}

Notes: * Calculation is based on the content of the active substance found by the HPLC method ( $\mathrm{Ph}$ Eur [13]) indicated on the certificate

Determination of Levomepromazine hydrochloride in a solution for injections of $25 \mathrm{mg} / \mathrm{mL}$ in a form of the corresponding sulfoxide obtained with diperoxyazelaic acid is more sensitive, faster and less labor-intensive in comparison with methods based on the formation of free radicals of Phentyasonium, as well as simpler than the method recommended by $\mathrm{Ph}$ Eur.

\section{Conclusions}

The procedure of indirect spectrophotometric determination of Levomepromazine hydrochloride as its S-oxide that was obtained reaction with diperoxyazelaic acid was first proposed for application in the practice of pharmaceutical analysis. The proposed spectrophotometric method for the determination of Levomepromazine hydrochloride is simple, reliable, sensitive and less time-consuming. The statistical analyses are in good agreement with those of the Oficial USP
XXXIX. The method can be successfully applied to the determination of Levomepromazine hydrochloride in pure substances as well as in Levomepromazine hydrochloride Solution for Injection. $\mathrm{LOQ}=2.9 \mu \mathrm{g} / \mathrm{mL}$. The reaction is specific for Levomepromazine hydrochloride. Other excipients such as anhydrous citric acid, monothioglycerol, sodium chloride did not interfere.

\section{References}

[1] Turkevich M, Vladzimirskaya O, Lesik R. Pharmaceutical chemistry (steroid hormones, synthetic substituted and heterocyclic compounds as drugs). Textbook. Vinnitsa: New Book, 2003;464 p.

[2] Khelfi, A., Azzouz, M., Abtroun, R., Reggabi, M., Alamir, B. Determination of Chlorpromazine, Haloperidol, Levomepromazine, Olanzapine, Risperidone, and Sulpiride in Human Plasma by Liquid Chromatography/Tandem Mass Spectrometry (LCMS/MS) Int J Anal Chem. 2018, Article ID 5807218, 13 pages https://doi.org/10.1155/2018/5807218

[3] Tanaka E, Nakamura T, Terada M, Shinozuka T, Hashimoto C, Kurihara K, Honda K. Simple and simultaneous determination for 12 phenothiazines in human serum by reversed-phase high-performance liquid chromatography. J Chromatogr B. 2007;854(1-2):116120. https://doi.org/10.1016/j.jchromb.2007.04.004

[4] Gradinaru J, Vullioud A, Eap CB, Ansermot N. Quantification of typical antipsychotics in human plasma by ultra-high performance liquid chromatography tandem mass spectrometry for therapeutic drug monitoring. $\mathrm{J}$ Pharm Biomed Analysis. 2014; 88: 36-44. https://doi.org/10.1016/j.jpba.2013.07.041

[5] Montenarh D, Hopf M, Maurer HH, Schmidt P, Ewald AH. Development and validation of a multi-analyte LCMS/MS approach for quantification of neuroleptics in whole blood, plasma, and serum.Drug Testing and 
Analysis.

2016;

$8(10)$ :

1080-

1089. https://doi.org/10.1002/dta.1923

[6] Kumazawa T, Hasegawa C, Uchigasaki S, Lee X-P, Suzuki O, Sato K. Quantitative determination of phenothiazine derivatives in human plasma using monolithic silica solidphase extraction tips and gas chromatography-mass spectrometry. J Chromatogr A. vol. 2011; 1218(18): 25212527. https://doi.org/10.1016/j.chroma.2011.02.070

[7] Progress in Chemical Toxicology. Vol. 5 / Ed. Abraham Stolman. Elsevier. 2013; 406 p.

[8] Mielech-Lukasiewicz K, Staskowska E. Sensitive and Rapid Voltammetric Determination of Phenothiazine and Azaphenothiazine Derivatives in Pharmaceuticals Using a Boron-doped Diamond Electrode. Anal Sci. 2015; 31(10): 961-969. https://doi.org/10.2116/analsci.31.961

[9] Sandulescu RV, Mirel SM, Oprean RN, Lotrean S. Comparative electrochemical study of some phenothiazines with carbon paste, solid carbon paste and glass-like carbon electrodes. Coll Czechoslovak Chem Commun. 2000; 65(6): 1014-1028. https://doi.org/10.1135/cccc20001014.

[10] Shlusar OI, Blazheevski MYe, Kisil YeP. Voltamperometric determination of thioridazine as its sulfoxide, obtained by acid Caro. Ukr Med Alm. 2012; 15 (3): 242-244.

[11] Le DC, Morin CJ, Beljean M, Siouffi AM, Desbène PL. Electrophoretic separations of twelve phenothiazines and $\mathrm{N}$-demethyl derivatives by using capillary zone electrophoresis and micellar electrokinetic chromatography with non ionic surfactant. J Chromatogr A. 2005; 1063(1-2): 235-240. https://doi.org/10.1016/j.chroma.2004.11.056

[12] Mercolini L, Bugamelli F, Kenndler E, Boncompagni G, Franchini L, Raggi MA. Simultaneous determination of the antipsychotic drugs Levomepromazine and clozapine and their main metabolites in human plasma by a HPLCUV method with solid-phase extraction. J Chromatogr B. 2007; $\quad$ 846(1-2): $273-280$. doi:10.1016/j.jchromb.2006.09.019
[13] European Pharmacopoeia $9^{\text {th }}$ Edition. European Directorate for the Quality of Medicines (EDQM). Council of Europe, 67075 Strasbourg Cedex, France 2016; 4016 p. [14] The United States Pharmacopeia, Thirty-Ninth Revision, and the National Formulary, Thirty-Fourth Edition. The United States Pharmacopeial Convention 12601 Twinbrook Parkway, Rockville, MD 20852

[15] Karpińska J, Wiszowata A, Skoczylas M. Simultaneous Determination of Levomepromazine Hydrochloride and Its Sulfoxide by UV-Derivative Spectrophotometry and Bivariate Calibration Method. Analytical letters. 2006; 39(6): 1129-1141. DOI: 10.1080/00032710600620609

[16] Karpińska J, Sokół A, Skoczylas M. An application of UV-derivative spectrophotometry and bivariate calibration algorithm for study of photostability of Levomepromazine hydrochloride. Spectrochimica Acta Part A: Molecular and Biomolecular Spectroscopy. 2008; 71(4): 1562-1564.DOI: 10.1016/j.saa.2008.06.007

[17] Puzanowska-Tarasiewicz H, Kuźmicka L, Karpińska J, Mielech-Lukasiewicz K. Efficient oxidizing agents for determination of 2,10-disubstituted phenothiazines. Anal. Sci. 2005; 21(10): 1149-1153. DOI: 10.2116/analsci.21.1149

[18] Shlusar OI, Blazheevski MYe. Spectrophotometric determination of Levomepromazine as it's sulphoxide obtained by peroxomonosulphate. Pharm J. 2012; 4(72): 34-38.

[19] Adegoke OA. Chemical derivatization methodologies for uv-visible spectrophotometric determination of pharmaceuticals Int. J. Pharm. Sci. Rev. Res., 2012; 14(2): 6-24.

[20] Blazheyevskiy MYe. Application of derivatization by means of peroxy acid oxidation and perhydrolysis reactions in pharmaceutical analysis : Monograph - Lviv : Ivan Franko National University of Lviv, 2017:106.

[21] Parker WE, Witnauer LP, Swern D. Peroxides. IV. ${ }^{2}$ Aliphatic Diperacids. J American Chem Society. 1957;79(8):1929-1931. doi:10.1021/ja01565a043 